
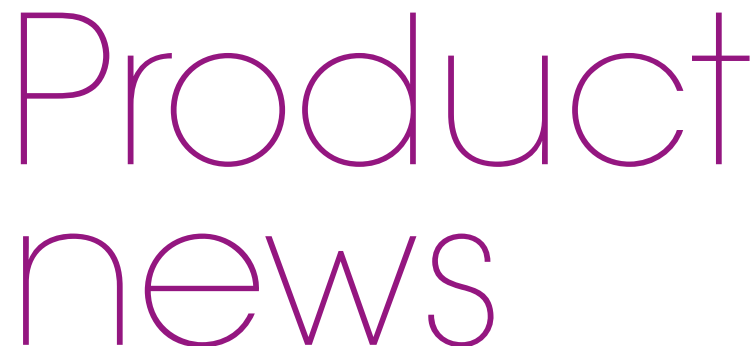

Product news is provided as a service to readers using text and images from the manufacturer, supplier or distributor and does not imply endorsement by BDJ Team. Normal and prudent research should be exercised before

purchase or use of any product mentioned.

\title{
SUSTAINABLE DENTAL HEALTH RESOURCES BY POST
}

Dental health startup Floe Oral Care has launched the UK's first $100 \%$ circular and eco-friendly subscription box. Every 12 weeks, the Floe subscription service delivers all the resources to maintain good oral health, without adding to the environmental crisis. The package includes:

- Two recyclable sugarcane based tubes of scientifically formulated toothpastes for different times of the day: whiten by DAWN and strengthened by DUSK

- Ultra-soft Swiss recyclable toothbrush with kind to gums bristles

- Biodegradable floss made from bamboo charcoal fibres

- A free returns label enabling customers to send all used products back to Floe to be turned into new ones.

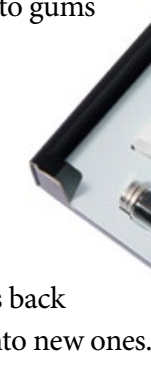

\section{DENTAL NURSES UNDERVALUED NO LONGER}

Dental nurses have been undervalued and underpaid for far too long. Colosseum Dental UK wants to show dental nurses want they mean to them - pandemic or no pandemic.

That's why Colosseum Dental UK has embarked on the 'Year of the Nurse'.

When other dental providers are pulling back or making redundancies, Colosseum Dental UK is doing the complete opposite. It has implemented pay rises to ensure that it offers very competitive salaries. It has also removed any criteria for higher pay opportunities associated with age to ensure total equality.

Colosseum Dental UK has committed
Floe Oral Care's flagship sustainable innovation will allow consumers to automate a routine that takes better care of not only their own health but also that of the planet. This will enable customers to build the foundations of an oral care programme that takes a proactive, long term approach to their general wellbeing, whilst also addressing the environmental impact of the dental industry.

Floe Oral

Care's strategic ambition is to broaden its reach to act as a digital platform connecting patients to dental clinics, as well as tracking and improving a broad range of health indicators through product innovation and behavioural change.

For more information visit www. getfloe.com.

\section{dentist 2020-2021}

$21^{\mathrm{s}}$

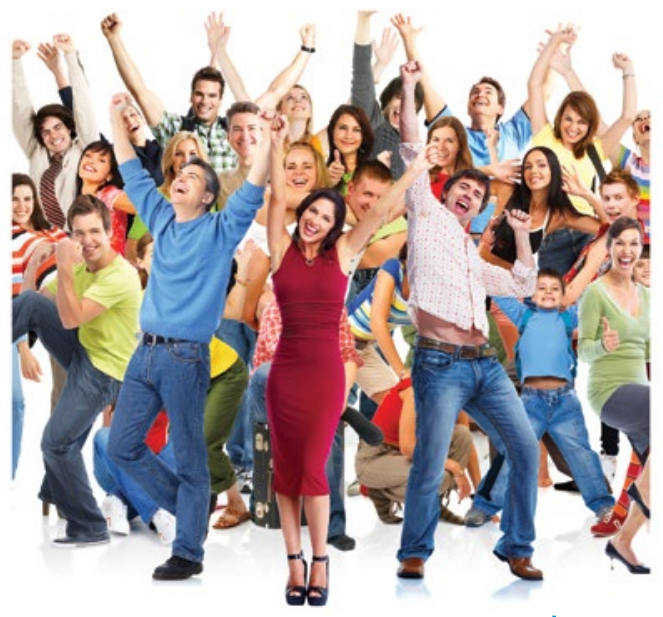

\section{LEARN TOGETHER AND FROM EACH OTHER}

The next British Dental Conference and Dentistry Show will provide an ideal platform for all dental professionals to finally come together safely in 2021 .

The event will once again feature lecture programmes dedicated to each team member, alongside an extensive trade exhibition demonstrating all the latest innovations on the market.

It will also provide an opportunity to catch up with friends and colleagues and share your experiences of what has been and continues to be a difficult time in dentistry. By learning together and from each other, we can all make it through.

The next British Dental Conference and Dentistry Show will be held on Friday 21 and Saturday 22 May 2021, Birmingham NEC, co-located with DTS.

For more information, visit www. thedentistryshow.co.uk, call 0207348 5270 or email dentistry@closerstillmedia. com. longer, thanking them for their continued dedication.

Dental nurses are the lifeblood of the dental practice. They deserve more - and they will get it at Colosseum Dental UK.

For more information about Colosseum Dental, visit www.colosseumdental.co.uk/ careers.
If you would like to promote your products or services direct to the dental industry in BDJ Team, call Andy May on 02078434785 or emaila.may@nature.com. 